\title{
Impact of Soil and Water Conservation Practice on Income in Chencha District, SNNP of Ethiopia
}

\author{
Musba Kedir (MSc) \\ Ethiopian Institute of Agricultural Research (EIAR), Agricultural Economics researcher
}

\begin{abstract}
Land degradation, in the form of soil erosion and nutrient depletion, threatens food security and the sustainability of agricultural production in many developing countries. As part of intervention activities a number of soil and water conservation practices have been promoted to smallholder farmers living in highly degraded and drought prone areas of the country. This study was conducted to examine the impact of SWC intervention on the livelihood of smallholder farm households in terms household income. To meet this objective primary data was collected in 2019 from 146 SWC program participants and 130 non-participants that were randomly selected from 3 intervention area and 3 counterfactual peasant associations in Chencha district of SNNP respectively. Descriptive and inferential statistics and propensity score matching (PSM) models were used to address the stated objectives. Results of the descriptive statistics showed that before matching there was statistically significant difference between program participants and their counterfactual households in terms of farm size and participation in petty trade from continuous independent variables and from categorical variables sex of household, education of household head, biological and physical conservation method, intercropping as well as bench terrace were significant in favor of program participants. Results of the PSM model revealed that SWC intervention result in significant difference between program participant and nonparticipant households in terms of household income.
\end{abstract} Keywords: Chencha, Income, land degradation, PSM model, Soil and water conservation

DOI: $10.7176 / \mathrm{CER} / 12-2-01$

Publication date: February $29^{\text {th }} 2020$

\section{Introduction}

The rain-fed agriculture contributes 58 percent to world's food basket from 80 percent agricultural lands (Raju et al. 2008). As a consequence of global population increase, water for food production is becoming an increasingly scarce resource, and the situation is further aggravated by climate change (Molden, 2007).The rain-fed areas are the hotspots of poverty, malnutrition, food insecurity, prone to severe land degradation, water security and poor social and institutional infrastructure (Rockstorm et al. 2007; Wani et al. 2007). Soil conservation program is, therefore, considered as an effective tool for addressing many of these problems and recognized as potential engine for agriculture growth and development in fragile and marginal rain-fed areas (Joshi et al. 2005; Ahluwalia and Wani et al. 2006).

Agriculture is the main sector of the Ethiopian economy and contributes approximately $42 \%$ to the gross domestic product (GDP) and employs over 80\% of the population (MoFED 2010; Diao 2010; ATA 2013). Despite its role, agricultural production is constrained by high climate variability where rainfall distribution is extremely uneven both spatially and temporally, and this has negative implications for the livelihoods of people (Georgis et al. 2010). Drought frequently results in crop failure, while high rainfall intensities result in low infiltration and high runoff causing enhanced soil erosion and land degradation. Land degradation in the form of soil erosion and declining land fertility is a serious challenge to agricultural productivity and economic growth (Lemenih 2004).

Ethiopia is a large country having 113 million hectares that is endowed with diverse climatic and physiographic condition, with a huge potential of water resource it accounts $122 \mathrm{BMC}$ annual surface runoff and 2.9 BMC groundwater, though it is characterized by uneven spatial and temporal distributions. Between $80 \%-90 \%$ of the country's surface water resources are found within four major river basins-Abay (Blue Nile), Tekeze, Baro Akobo and Omo Gibe and rainfall in the country ranges between $2250 \mathrm{~mm}$ per year in the south-western highlands and less than $200 \mathrm{~mm}$ in the North and South-East with a further decrease of less than $100 \mathrm{~mm}$ per year in the North. Temperatures are also very much modified by the varied altitude.

Soil erosion is one of the biggest global environmental problems resulting in both on-site and off-site effects. The economic implication of soil erosion is more serious in developing countries because of lack of capacity to cope with it and also to replace lost nutrients. These countries have also high population growth which leads to intensified use of already stressed resources and expansion of production to marginal and fragile lands. Such processes aggravate erosion and productivity declines, resulting in a population-poverty-land degradation cycle.

According to Lulseged T. and Paul L. G. Vlek (2008) Rapid population growth, cultivation on steep slopes, clearing of vegetation, and overgrazing are the main factors that accelerate soil erosion in Ethiopia. The annual rate of soil loss in the country is higher than the annual rate of soil formation rate. Annually, Ethiopia losses over 1.5 billion tons of topsoil from the highlands to erosion which could have added about 1.5 million tons of grain to 
the country's harvest. This indicates that soil erosion is a very serious threat to food security of people and requires urgent management intervention.

The country has a history of soil conservation and watershed management initiatives dating back to the 1970 s. The basic approach has shifted from top-down infrastructure solutions to community-based approaches. There is now a supportive policy and legal framework in the form of policies that facilitate decentralized and participatory development, institutional arrangements that allow and encourage public agencies at all levels to work together, and an approach to natural resources that reacts local legislation and tenure practices.

The main environmental problems of the country include land degradation, soil erosion, and deforestation of natural resource, desertification and loss of biodiversity, and recurrent drought resulting in declining productivity and continuing in food shortage. Huge part of the country has fragile ecosystem which includes dry, humid, subhumid, semi-arid, semi dry and arid conditions. This is frequently exposed to desertification and recurrent drought. The highlands constituting majority of land is currently under stress due to rising population pressure and their conservative socio economic practices. The extent of fertile land available for agriculture is decreasing due to increased soil erosion. Land degradation is caused by deforestation and faulty management practices (cultivating along the slope) of the natural resources, (soil, forest resource and water). It leads to both loss of agricultural production and increased risks of flooding, siltation and sedimentation.

In recent years, environment has become a key issue in Ethiopia. The main environmental problems of the country include land degradation, soil erosion, and deforestation of natural resource, desertification and loss of biodiversity, and recurrent drought resulting in declining productivity and continuing in food shortage. Huge part of the country has fragile ecosystem which includes dry, humid, sub-humid, semi-arid, semi dry and arid conditions. This is frequently exposed to desertification and recurrent drought. The highlands constituting majority of land is currently under stress due to rising population pressure and their conservative socio economic practices. The extent of fertile land available for agriculture is decreasing due to increased soil erosion. Land degradation is caused by deforestation and faulty management practices (cultivating along the slope) of the natural resources, (soil, forest resource and water). It leads to both loss of agricultural production and increased risks of flooding, siltation and sedimentation. The soil erosion and deforestation reduces the production potential of land and the overall utility of land resource, and thus making it unsustainable to produce sufficient to feed for the growing population. It also increases farmers' susceptible to food shortages and low income which threatens their survival.

\subsection{Statement of the Problem}

Soil erosion is a severe and continuous ecological problem in the north-western Highlands of SNNP Region, Bekele, et al (2015). Limited knowledge of farmers to practice soil and water conservation technologies is one of the major causes that have resulted in accelerated soil erosion.

Although efforts by most projects made on soil and water conservation measures, little was known about the contribution of the introduced soil and water conservation technologies on household income. This study will be therefore conducted to assess the impact of the soil and water conservation technologies on household income in Chencha district of SNNPR.

\subsection{Objectives of the study}

The general objective of the study is to analyze impact of soil and water conservation on farm income among farm households.

\section{Specific objectives include}

To assess socio-economic factors that affect use of soil and water conservation practices in the study area. To analyze the impact of soil and water conservation practice on farm income in the study area.

\section{RESEARCH METHODOLOGY}

\subsection{Description of the Study Area}

\subsubsection{Geographical Location}

This study was conducted in chencha district in South Nations Nationalities and Peoples of Ethiopia. Chencha district is one of the 15 districts in Gamo Gofa zone of SNNP region of Ethiopia. Astronomical location of the district is between $37^{\circ} 29^{\prime} 57^{\prime}$ " to $37^{\circ} 39^{\prime} 36^{\prime \prime}$ "East Longitude and between $6^{\circ} 8^{\prime} 55^{\prime \prime}$ and $6^{0} 25^{\prime} 30^{\prime \prime}$ North Longitude. It is located about $521 \mathrm{~km}$ south of Addis Ababa the capital city of Ethiopia and $36 \mathrm{~km}$ away from the zonal capital of Arba Minch. The district is subdivided in to 45 rural kebeles and 5 transition towns. The district is bordered by four districts; Aribaminch Zuria in the south and southeast; Mirab Abaya in the east; Kucha in the North and Northwest; and Dita in the West.

\subsubsection{Population of the Study Area}

According to district Finance and Economic office estimation, in 2016, the total population was estimated that 154,701 from this 69,842 are male and 84,859 are females implying, 54.9\% of women. The household head number was male 17,621 and female 6,113 total 23,734 . The district has high population number per square kilo meter 
which estimated 434 persons $/ \mathrm{km}^{2}$.

\subsubsection{Land Use Systems and Coverage of the Study Area}

According to the district's Agriculture and Natural Resource Office, the total area of the district is estimated to be 37,360 hectares. The average land holding per household is estimated to be 0.35 hectare. The major land uses patterns are private holding (farming), communal (grazing) and forest land. The current land use coverage's are cultivation of annual crop is $58 \%$, Perennial crop is $12 \%$ and grazing lands is $6.6 \%$. Among the total area, $9.4 \%$ of the land is currently unutilized and the remaining (15\%) is covered by shrub/bush and natural and plantation forests. The farming practice in the district is mixed farming systems which are crop production and livestock keeping. The major means of livelihood in the area are subsistence rain fed agriculture, traditional weaving and involvement in off-farm activities (Agriculture Office 2017).

\subsection{Sampling Technique and sample size}

To determine the sample size of the study area, this study used Yamane's formula (1977) with 95 confidence levels. The reason for using this formula is because this kind of formula is valid for survey researchers which compose large population. Moreover, the population under investigation is homogenous in its socio-economic and geographic context and the formula enables to get manageable sample size.

$$
\begin{aligned}
& \mathrm{n}=\frac{\mathrm{N}}{1+\mathrm{N}(\mathrm{e})^{2}}=\frac{900}{1+900(0.05)^{2}}=\frac{2700}{7.75}=276 \\
& \mathrm{n}=\text { sample size } \mathrm{N}=\text { total population of the sample } \\
& \mathrm{e}=\text { acceptable error in social science. }
\end{aligned}
$$

FGD was undertaken in each Kebele as well as discussions with experienced and knowledgeable key informants in the target areas. The number of participants in each group ranged from 9-11 farmers.

\subsection{Method of Data Analysis}

\subsubsection{Descriptive and inferential statistics}

Descriptive statistics such as mean, standard deviation, percentages, frequency, charts, and graphs, used to describe different categories of sample units with respect to the desired socioeconomic characteristics. Moreover, inferential statistics such as chi-square test (for categorical variables) and t-test (for continuous variables) were used to compare and contrast different categories of sample units with respect to the desired characters so as to draw some important conclusions.

\subsubsection{Econometric analysis}

\section{Propensity score matching method}

For more than two decades, advanced statistical methods known as propensity score (PS) techniques, have been available to aid in the evaluation of cause-effect hypotheses in observational studies. None the less, PS techniques have not yet been used widely in psychological research" (Harder, Stuart, \& Anthony, 2010

In an observational study, covariates are usually not balanced between treatment groups. Rosenbaum and Rubin have demonstrated that observed covariates are balanced at each value of propensity score; it means that households in treated and control groups with equal propensity score have the same distributions of the observed covariates.

The propensity score can be understood as a proxy between cases and covariates influencing the exposure, so it can be used instead of additional analyses of the covariates to simplify the analysis. Therefore, the propensity score as a proxy variable aggregates multiple confounding factors into a single dimension.

This approach is, for example, widely applied when evaluating labor market policies (e.g., Bryson et al, 1997; Heckman et al, 1997; Dehejia and Wahba, 1999; Manski and Garfinkel, 2002; Sianesi, 2004). In the empirical labor economics literature, matching has been used to evaluate the returns from education (e.g., Blundell et al, 2005; Brand and Halaby, 2006) and the union membership wage premium (Eren, 2007). Empirical examples can be found in very diverse fields of observational studies whenever the researcher aims to evaluate the effect of a variable (often of some policy relevance) on another. In the demo-economic literature, researchers are often interested in the evaluation of the effects of demographic events, like childbearing or marital disruption, on economic variables, like wellbeing and labor force participation (e.g., Aassve et al, 2007; Aassve and Arpino, 2007). The approach is also applied in the educational literature to study the effect of educational programs and policies on students' performances (e.g., Hong and Raudenbush, 2006).

\section{Specification of the PSM method}

According to Caliendo and Kopeinig (2008), the estimation of the impact of household's adoption of SWC on a given farm income $(\mathrm{Y})$ is specified as:

$\tau_{i}=Y_{i}\left(D_{i}=1\right)-Y_{i}\left(D_{i}=0\right)$

Where $\tau i$ is treatment effect (effect due adoption of SWC), Yi is farm income of household $i$, Di is whether household $i$ has got the treatment or not (i.e., whether a household is use or not).

However, one should notice that) $Y i(D i=1)$ and $\mathrm{Yi}(D i=0)$ cannot be observed for the same household at 
the same time. Depending on the position of the household in the treatment (use of SWC practices), either $Y i$ ( $D i$ $=1)$ or $Y i(D i=0)$ is unobserved outcome (called counterfactual outcome). Due to this fact, estimating individual treatment effect $\tau_{i}$ is not possible and one has to shift to estimating the average treatment effects of the population than the individual one. Most commonly used average treatment effect estimation is the 'average treatment effect on the treated $\left(\tau_{A T T}\right)$, and specified as:

$\tau_{A T T}=E(\tau / D=1)=E[Y(1) / D=1]-E[Y(0) / D=1]$

As the counterfactual mean for those being treated, E [Y $(0) / D=1]$ is not observed, one has to choose a proper substitute for it in order to estimate ATT. One may think to use the mean outcome of the untreated individuals, $E[Y(0) / D=0]$ as a substitute to the counterfactual mean for those being treated, $\mathrm{E}[\mathrm{Y}(0) / \mathrm{D}=1]$. However, this is not a good idea especially in non-experimental studies, since it is likely that components which determine the treatment decision also determine the outcome variable of interest.

In this particular case, variables that determine household's decision to adopt SWC practices could also affect household's farm income. Therefore, the outcomes of individuals from treatment and comparison group would differ even in the absence of treatment leading to a self-selection bias.

By rearranging, and subtracting $E[Y(0) / D=0]$ from both sides of equation (2), one can get the following specification for ATT.

$E[Y(1) / D=1]-E[Y(0) / D=0]=0$

Both terms in the left hand side are observables and ATT can be identified, if and only if E[Y $(0) / \mathrm{D}=1]-$ $\mathrm{E}[\mathrm{Y}(0 / \mathrm{D}=0]=0$. i.e., when there is no self-selection bias. This condition can be ensured only in social experiments where treatments are assigned to units randomly (i.e., when there is no self-selection bias). In nonexperimental studies one has to introduce some identifying assumptions to solve the selection problem. The two strong assumptions to solve the selection problem are Conditional Independence Assumption (CIA) and Common support region assumption.

\section{Estimation of the propensity scores}

Propensity score involves a series of empirical steps. First, logit model that predicts the probability of each household adopting SWC (propensity score) as a function of observed household and community characteristics was estimated, using a sample of participants and non-participants. In estimating the propensity score, the dependent variable used in the model was a binary variable a value of 1 for user of SWC and 0 otherwise.

The estimates of individual adoption using logit model are useful for two reasons. First, it gives some insight regarding the observable variable that should be included in the balancing function. Second, it provides a better understanding of adoption of SWC by the kebeles households.

According to Gujrat (2004), the logistic distribution function for the determining factors for WSM of the household can be specified as:-

$\mathrm{p}(\mathrm{i})=\frac{1}{1+e^{-z i}}$

Where $p$ ( $i)$ is a probability of a household being diversified for $i^{\text {th }}$ household and $\mathrm{Z}(\mathrm{i})$ is a function of $\mathrm{m}$ explanatory variables $(\mathrm{Xi})$ and expressed as:

$Z(i)=\beta_{o}+\beta_{1} X_{1}+\beta_{2} X_{2}+\cdots \beta_{m} X_{m}$

Where $\beta_{0}$ is the intercept and $\beta_{i}$ is the slopes parameter in the intercept in the model which is estimated using maximum likelihood method.

The probability that a household belongs to not adopt is:

$(1-\mathrm{Pi})=\frac{1}{1+\mathrm{e}^{\mathrm{z}(\mathrm{i})}}$

Therefore,

$\left(\frac{P_{i}}{1-p_{i}}\right)=\frac{1+e^{Z(i)}}{1+e^{-Z(i)}}=e^{z(i)}$

And

$\frac{P_{(i)}}{1-p_{(i)}}=\frac{1+e^{z(i)}}{1+e^{-z(i)}}=e^{\beta_{o}}+\sum_{i-1}^{m} \beta_{i} Y_{i}$

Taking the natural logarithms of the odds ratio of equation (15) will result in what is known as the logit model as included below:

$\ln \left(\frac{P_{(i)}}{1-p_{(i)}}\right)=\ln \left[e^{\beta_{o}}+\sum_{i=1}^{m} \beta_{i} x_{i}\right]=Z_{(i)}$

If the disturbance term $\mathrm{U}_{\mathrm{i}}$ is taken in to account the logit model becomes:

$Z_{I=} \beta_{O}+\sum \beta_{i} X_{i}+U_{i}$

Choice of matching algorithm

After estimation of the propensity score, seeking an appropriate matching estimator is the major task of program evaluator. There are different matching estimators in theory. However the most commonly applied matching estimators are Nearest Neighbor matching (NN) Caliper matching, Kernel and local linear matching (Smith and Todd, 2005). The performance of different matching algorithms varies case-by-case and depends largely on the 
data sample (Caliendo and Kopeing, 2008).

Testing matching quality and overlap assumption

The "balancing properties" of the data was checked by testing that treatment and comparison observations had the same distribution (mean) of propensity scores and of control variables within grouping (roughly quintiles) of the propensity score.

\section{RESULTS AND DISCUSSION}

This chapter mainly presents the findings of the study with an appropriate level of discussion. It is divided in to two sub-headings that could give a brief account of the subjects that were being investigated by the study. The first sub-heading presents descriptive analysis of sample households. The second sub-heading is econometric model for impact of soil and water conservation on income by sample households.

\subsection{Descriptive Analysis}

In this section of analyses descriptive statistics such as mean, standard deviation, percentage, t-test and chi-square test were employed using SPSS version 20 and STATA 15 software programs. In this study, use of a technology refers to farmers who used SWC practices and those farmers who do not used on their farm land.

\subsubsection{Descriptive statistics for socioeconomic variables in the study}

A combination of different descriptive, the means and standard deviation and inferential, the t-test and $X^{2}$-test, statistics for explanatory variables of sample households were performed on the house hold level data to inform the subsequent empirical data analysis.

The descriptive and inferential results presented on Table 3 show from continuous independent variables, there was statistically significant difference between users and non-user household in terms of farm size and income from petty trade, in favor of the users of SWC practices.

Table 1. Descriptive statistics of continuous independent variables

\begin{tabular}{lllll}
\hline Variables & \multicolumn{2}{c}{ Mean across adoption categories } & t-test & P Value \\
\cline { 2 - 3 } & user & Non-user & & \\
\cline { 2 - 3 } family size & 2.000 & 2.000 & 2.50 & 0.61 \\
Farm size & 0.193 & 2.324 & $2.324^{* *}$ & 0.02 \\
Age of household head & 44.00 & 45.00 & 0.70 & 0.46 \\
Income from Petty trade & 793.69 & 527.089 & $2.84^{* * *}$ & 0.004 \\
\hline
\end{tabular}

Source: own survey, $* * *$ and $* *$ indicates that at $1 \% \& 5 \%$ significance level respectively

The descriptive and inferential statistics results presented in Table 4 show that $85.38 \%$ of users were male headed households. Regarding to education status of households $36.92 \%$ were illiterate, $33.85 \%$ was completed primary school, $26.15 \%$ of the household finalized secondary school. On the other hand, $97.69 \%$ and $98.46 \%$ user households participated on biological and Physical conservation methods respectively. Other remaining categorical variables, which have significant difference between users and non-user households, are described in table 2 .

Table 2. Descriptive statistics for categorical variables

\begin{tabular}{|c|c|c|c|c|}
\hline Variable & $\%$ of User & \% of Non-User & $X^{2}$ & P-value \\
\hline \multicolumn{5}{|l|}{ Sex of House hold } \\
\hline Male & 85.38 & 69.18 & \multirow{2}{*}{10.14} & \multirow{2}{*}{0.001} \\
\hline Female & 17.12 & 30.82 & & \\
\hline \multicolumn{5}{|l|}{ Education } \\
\hline Illiterate & 36.92 & 49.32 & \multirow{4}{*}{12.5} & \multirow{4}{*}{0.006} \\
\hline Primary School & 33.85 & 38.36 & & \\
\hline Secondary School & 26.15 & 10.96 & & \\
\hline Above secondary school & 3.08 & 1.37 & & \\
\hline \multicolumn{5}{|c|}{ Biological soil conservation } \\
\hline No & 2.31 & 49.32 & \multirow{2}{*}{54.5} & \multirow{2}{*}{0.0001} \\
\hline Yes & 97.69 & 50.68 & & \\
\hline \multicolumn{5}{|c|}{ Physical conservation method } \\
\hline No & 1.54 & 36.3 & \multirow{2}{*}{52.08} & \multirow{2}{*}{0.0001} \\
\hline Yes & 98.46 & 63.7 & & \\
\hline \multicolumn{5}{|l|}{ Use of grass Strip } \\
\hline Very Effective & 20 & 6.85 & \multirow{3}{*}{52.08} & \multirow{3}{*}{0.0001} \\
\hline Moderately Effective & 49.23 & 49.32 & & \\
\hline Less Effective & 30.77 & 43.84 & & \\
\hline \multicolumn{5}{|l|}{ Intercropping } \\
\hline Very Effective & 6.92 & 10.27 & \multirow{2}{*}{7.99} & \multirow{2}{*}{0.099} \\
\hline Moderately Effective & 53.85 & 36.99 & & \\
\hline
\end{tabular}




\begin{tabular}{|c|c|c|c|c|}
\hline Less Effective & 39.23 & 52.74 & & \multirow{5}{*}{0.67} \\
\hline Bench terrace & & & \multirow{4}{*}{0.78} & \\
\hline Very Effective & 30.77 & 24.66 & & \\
\hline Moderately Effective & 30 & 19.86 & & \\
\hline Less Effective & 51.54 & 44.52 & & \\
\hline \multicolumn{5}{|l|}{ Extension Service } \\
\hline $\begin{array}{l}\text { No } \\
\text { Yes }\end{array}$ & $\begin{array}{r}7.69 \\
92.31\end{array}$ & $\begin{array}{l}21.92 \\
78.08\end{array}$ & 10.78 & 0.001 \\
\hline
\end{tabular}

Source: own survey (2016), $* *$ and $* * *$ indicates $5 \%$ and $1 \%$ of significance probability level

\subsection{Econometric Analysis}

\subsubsection{Propensity score matching (PSM)}

This section presents the results of the logistic regression model which is used to estimate propensity scores for matching user households with non-user. As indicated earlier, the dependent variable in this model is binary variable indicating whether the household has used soil and water conservation or not and the outcome variable is the farm income. In the estimation, data from the two groups; namely, user and non- user households were pooled such that the dependent variable takes a value 1 if the household is user of SWC and 0 otherwise.

Table 3 shows the estimation results of the logit model. The estimated model appears to perform well for our intended matching exercise. The pseudo- $\mathrm{R}^{2}$ value is 0.2376 , which is fairly low. A low pseudo- $\mathrm{R}^{2}$ value means that household used SWC practices, do not have many distinct characteristics overall and as such finding a good match between users of the practice and non-user and the pseudo- $\mathrm{R}^{2}$ indicates how well independent variables explain the probability of using it.

Table 3. Propensity score matching estimation (logit model)

\begin{tabular}{lcccccc}
\hline Use soil con & Coef. & Std.Err. & $\mathrm{Z}$ & $\mathrm{P}>\mathrm{Z}$ & {$[95 \%$ Conf. } & Interval] \\
\hline age of HH head & 0.018 & 0.014 & 1.290 & 0.198 & -0.009 & 0.045 \\
sex of HH head & 1.226 & 0.381 & 3.220 & $0.001 * * *$ & 0.479 & 1.973 \\
Education & 0.053 & 0.184 & 0.280 & 0.776 & -0.309 & 0.414 \\
Family size & 0.314 & 0.716 & 0.440 & 0.661 & -1.089 & 1.716 \\
Farm size & 1.794 & 0.812 & 2.210 & $0.027^{* *}$ & 0.203 & 3.385 \\
Biological & 1.115 & 0.471 & 2.370 & $0.018^{* *}$ & 0.193 & 2.038 \\
conservation & & & & & & \\
Use of physical & 2.027 & 0.964 & 2.100 & $0.035^{* *}$ & 0.138 & 3.916 \\
con. & & & & & & 0.084 \\
Use grass strip & -0.350 & 0.221 & -1.580 & 0.114 & -0.783 & 0.669 \\
Use intercropping & 0.209 & 0.235 & 0.890 & 0.375 & -0.252 & -0.120 \\
Bench terrace & 0.237 & 0.182 & 1.300 & 0.193 & -15.425 & -5.019 \\
cons & -10.222 & 2.655 & -3.850 & 0.000 & &
\end{tabular}

Note: $* * * \& * *$, show significance at $1 \%$ and $5 \%$ level, respectively

Figure 4 portrays the distribution of the household with respect to the estimated propensity scores. In case of treatment households, most of them are found in partly the middle and partly in the right side of the distribution. On the other hand, most of the control households are partly found in the center and partly in the left side of the distribution.
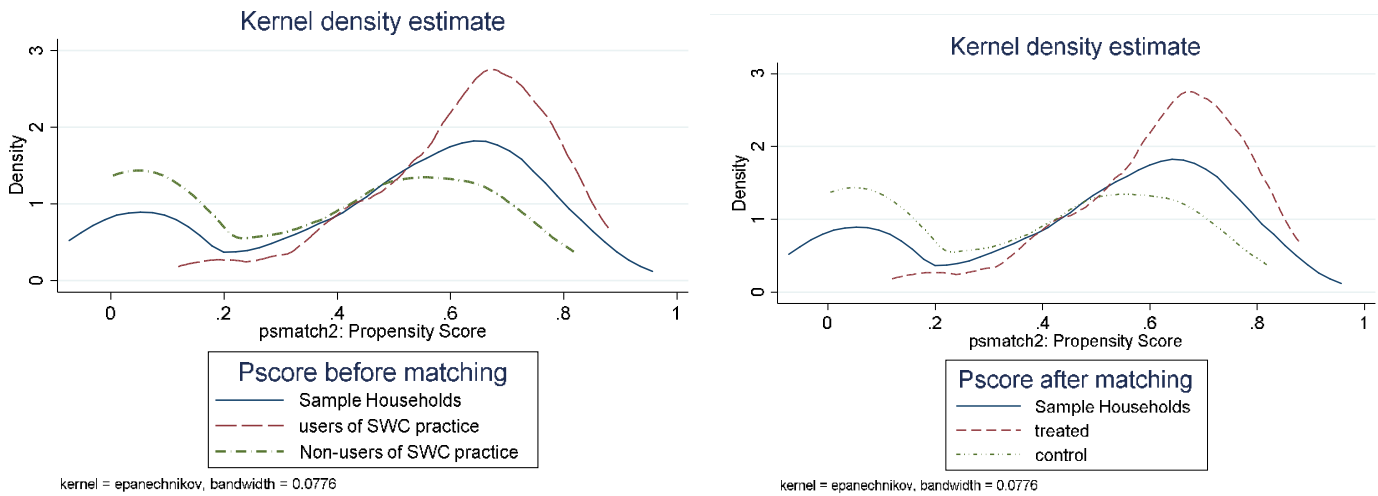

Figure 1.Figure 1. Kernel density of propensity score before and after matching

Source: own sketch (2020) 


\subsubsection{Matching adopters and non-adopter households}

The estimated propensity scores vary between 0.1280 and 0.8756 , with a mean of 0.6153 for treatment households and between 0.0036 and 0.8139 with a mean of 0.3424 , for control households (Table 4). The common support region would then lies between 0.0036 and 0.8756 that is the minimum and the maximum value of treated and control households, respectively. This ensures that any combination of characteristics observed in the treatment group can also be observed among the control group. In other words, households whose estimated propensity scores are less than 0.0036 and larger than 0.8756 are not considered for matching exercise. This is because no matches can be made to estimate the average treatment effects on the ATT parameter when there is no overlap between the treatment and non-treatment group (Bryson et al., 2002). As a result of this restriction, 7 households from treated and 53 households from the control were discarded.

Table 4.Region of common support

\begin{tabular}{llllll}
\hline Variable & Obs & Mean & Std. Dev & Min & Max \\
\hline pscore if usewsm $=1$ & 146 & 0.6153 & 0.1625 & 0.1280 & 0.8756 \\
pscore if usewsm=0 & 130 & 0.3424 & 0.2699 & 0.0036 & 0.8139 \\
pscore & 276 & 0.4710 & 0.2635 & 0.0036 & 0.8756 \\
\hline
\end{tabular}

Source: Own estimation (2019)

\subsubsection{Choice of matching algorithm}

Selecting matching estimator has its own criteria. The final choice of a matching estimator was guided by different criteria such as equal means test referred to as the balancing test, pseudo- $\mathrm{R}^{2}$ and matched sample size (Deheia and Wahba, 2002). Balancing test is a test conducted to know whether there is statistically significant difference in mean value of per-treatment characteristics of the two groups of the respondent and preferred when there is no significant difference. Accordingly, matching estimators were evaluated by matching adopters and non-adopter households in common support region. Therefore, a matching estimator having balanced (insignificant mean difference in all explanatory variables) mean bears a low pseudo- $\mathrm{R}^{2}$ value and also the one that results in large matched sample size is preferred.

Table 5. Performance of matching estimators

\begin{tabular}{llll}
\hline Matching Algorithm & Balancing test & Pseudo R2 & Sample size \\
\hline Kernel & & & \\
0.01 & 6 & 0.237 & 216 \\
0.1 & 6 & 0.237 & 216 \\
$\mathbf{0 . 2 5}$ & $\mathbf{6}$ & $\mathbf{0 . 2 3 7}$ & $\mathbf{2 1 6}$ \\
Caliper & & & 222 \\
0.01 & 9 & 0.0496 & 220 \\
0.1 & 9 & 0.0496 & \\
Radius caliper & & & 212 \\
0.1 & 9 & 0.153 & $\mathbf{2 2 0}$ \\
$\mathbf{0 . 0 1}$ & $\mathbf{8}$ & $\mathbf{0 . 1 2 4}$ & \\
\hline
\end{tabular}

Source: Own estimation result, 2019

\subsubsection{Testing the balance of propensity scores and covariates}

Ensuring good balance between treated and control group is the most important step in using any propensity score method. The before and after matching covariate balancing tests presented on table 6 suggested that the proposed specification of the propensity score is fairly successful in balancing the distribution of covariates between the two groups as indicated by decreasing pseudo R2, decreasing mean standardized bias for all regions and the insignificant $\mathrm{p}$-values of the likelihood ratio test.

Table 6. Propensity score and covariate balance

\begin{tabular}{lllllllll}
\hline Sample & PsR2 & LRchi2 & P $>$ chi2 & Mean Bias & MedBias & B & R & \%Var \\
\hline Unmatched & 0.264 & 100.76 & 0.000 & 39.7 & 37.5 & 125.1 & 0.14 & 38 \\
Marched & 0.069 & 25.00 & 0.123 & 15.7 & 11.2 & 63.8 & 1.22 & 15 \\
\hline
\end{tabular}

Source: Own estimation result based on household responses, 2019

Different impact estimators were employed to get estimated treatment effect. Table 7 depicts the average impact of using soil conservation methods on farm income for the study area of interest following kernel matching, caliper and radius caliper matching techniques. Accordingly, there is at least some evidence to support the hypothesis soil conservation method has a positive and significant impact on income growth in the district.

\subsubsection{Treatment effect on the treated (ATT)}

This sub-section provides evidence as to whether or not the use of soil conservation practice has brought significant changes on farm income. The Kernel estimator with band width 0.25 , the best matching estimator for the data at hand, was used to compute the average impact of soil conservation among adopter households. 
Table 7.Average treatment effect on the treated (ATT)

\begin{tabular}{cccccc}
\hline Variable $($ birr $)$ & ATT on Treated & ATT on Control & Diff. & SE & T-value \\
\hline Farm Income KM(0.25) & 2292.308 & 1874.231 & 418.07 & 183.97 & $2.270^{* *}$ \\
Farm Income KM(0.5) & 2271.37 & 2089.47 & 181.89 & 158.89 & 1.15 \\
Farm Income C $(0.1)$ & 2192.85 & 1915.71 & 277.14 & 211.50 & 1.31 \\
Farm Income C $(0.01)$ & 2271.37 & 1928.62 & 342.74 & 208.12 & $1.65^{*}$ \\
\hline
\end{tabular}

Note: $\mathrm{SE}=$ Bootstrapped standard errors with 100 replications;

\section{Conclusion}

Soil erosion is one of the biggest global environmental problems resulting in both on-site and off-site effects. The economic implication of soil erosion is more serious in developing countries because of lack of capacity to cope with it and also to replace lost nutrients. Soil erosion is a severe and continuous ecological problem in the northwestern Highlands of SNNP Region specifically in the study area. Because of this problem, SWC practice was implemented by government, farmers and non-governmental organization in the three severely eroded kebeles four long period of time.

This study is targeted to analyze impact of SWC practices on income in Chencha district of SNNP. To analyze the data descriptive statistics and econometric statistics was used. The descriptive statistics like t-test and chi square test revealed that there was significant difference between two continuous variables which were, farm size and income from petty trade. From descriptive statistics, Sex of House hold, Education, Biological soil conservation, Physical conservation method, Use of grass Strip, Intercropping and Extension Service were significant at different significant level.

Regarding PSM model, after several PSM estimation steps we obtained significant difference between treated and control households. Means that, those treated households were higher income compared to control households. Therefore, SWC practice should be strengthened to increase household income and for better welfare for study area and other degraded areas of Ethiopia.

\section{REFFERENCE}

Raju et al. (2011) Determinants and Macroeconomic Impact of Remittances in Sub-Saharan Africa

Molden, (2007) Pathways for increasing agricultural water productivity

Wani et al. (2007) Effect of metal tolerant plant growth promoting Bradyrhizobium sp. (vigna) on growth, symbiosis, seed yield and metal uptake by green gram plants

Joshi et al. (2007) Wheat improvement in India: present status, emerging challenges and future prospects

Wani, S P and Garg, K K (2009) Watershed Management Concept and Principles. In: Best-bet Options for Integrated Watershed Management Proceedings of the Comprehensive Assessment of Watershed Programs in India, 25-27 July 2007, ICRISAT Patancheru, Andhra Pradesh India.

MoFED 2010; Sustainable Development and Poverty Reduction). (Draft). Addis Ababa

Diao, X. et al. (2010) The Role of Agriculture in African Development, World Development (2010), doi:10.1016/j.worlddev.2009.06.

ATA 2013; Status of soil resources resources in Ethiopia Ethiopia and priorities for sustainable management, GSP for Eastern and Southern Africa Mar 25-27, 2013, Nairobi, Kenya

Lemenih, Mulugeta (2004). Effects of land use changes on soil quality and native flora degradation and restoration in the highlands of Ethiopia. Diss. (sammanfattning/summary) Uppsala: Sveriges lantbruksuniv. Acta Universitatis Agriculturae Sueciae. Silvestria, 1401-6230; 306

Lulseged Tamene and Paul L. G. Vlek (2008) Soil Erosion Studies in Northern Ethiopia

Bekele, et al (2015) factors determining allocation of land for improved wheat variety by small holder farmers of northern Ethiopia

Harder, V. S., Stuart, E. A., \& Anthony, J. C. (2010). Propensity score techniques and the assessment of measured covariate balance to test causal associations in psychological research. Psychological Methods, 15(3), 234249.

Bryson et al, (1997) Positive and negative affect recognition in schizophrenia: a comparison with substance abuse and normal control subjects

Heckman et al, (1997) Todd, Matching As An Econometric Evaluation Estimator: Evidence from Evaluating a Job Training Programme, The Review of Economic Studies, Volume 64, Issue 4, Pages 605-654, https://doi.org/10.2307/2971733;

Dehejia and Wahba, (1999) Causal Effects in Nonexperimental Studies: Reevaluating the Evaluation of Training Programs, Journal of the American Statistical Association

Sianesi (2004); an Evaluation of the Swedish System of Active Labor Market Programs in the 1990s.

Bryson, (2002); the use of Propensity Score Matching in the Evaluation of active Labor Market Policies.

Eren, 2007; Social sources of information in opportunity recognition: Effects of mentors, industry networks, and 
professional forums.

Aassve et al, 2007; Mmarital disruption and economic well - being: a comparative analysis.

Guanglei Hong \& Stephen W Raudenbush (2006) Evaluating Kindergarten Retention Policy, Journal of the American Statistical Association, 101:475, 901-910, DOI: 10.1198/016214506000000447Kopeinig (2008)

Smith and Todd, (2005); Does matching overcome Lalonde's critique of nonexperimental estimators? 